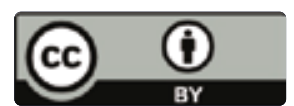

\title{
RELACIÓN ENTRE CITOLOGÍA, BIOPSIA Y COLPOSCOPÍA EN CÁNCER CÉRVICO UTERINO
}

\author{
RELATIONSHIP BETWEEN CYTOLOGY, BIOPSY AND \\ COLPOSCOPY IN CERVICAL CANCER
}

\footnotetext{
Zamora-Julca Roxana Elizabeth ${ }^{1, a}$, Ybaseta-Medina Jorge ${ }^{2, a}$, Palomino-Herencia Adrián $^{\mathrm{b}}$

Facultad de Medicina Humana de la Universidad Nacional San Luis Gonzaga. Ica, Perú

1. Residente de Ginecología y Obstetricia del Hospital Santa María del Socorro de Ica

2. Docente de la Universidad Nacional San Luis Gonzaga de Ica, Perú.

3. Médico Asistente del Hospital Santa María del Socorro de Ica

a. Jefe el Departamento de Ginecología y Obstetricia Hospital Santa María del Socorro

b. Médico Asistente del Hospital Santa María del Socorro
}

doi: https://doi.org/10.35563/rmp.v8i1.13

\section{Correspondencia:}

Zamora Julca Roxana.

Número de celular: +51979433916 Correo Electrónico:

roxyzaju15@hotmail.com

Domicilio: Villa el Médico A-13, Ica, Perú.

\section{Contribuciones De Autoría:}

ZJRE, YMJ, PHA: Contribuciones

en la concepción y diseño del manuscrito, recolección, análisis e interpretación de los datos, redacción y revisión crítica del contenido del manuscrito y aprobación final del artículo.

Conflicto De Intereses: No declarados.

Financiamiento: Autofinanciado.

\section{Como Citar}

Zamora-Julca Roxana Elizabeth, Ybaseta-Medina Jorge, PalominoHerencia Adrián. Relación entre Citología, Biopsia y Colposcopía en Cáncer Cérvico Uterino. Rev méd panacea 2019;8(1): 31-45

Recibido: 03 - 03 - 2019 Aceptado: 20 - 04 - 2019 Publicado: 23 - 04 - 2019

\section{RESUMEN}

Objetivo: Determinar la relación que existe entre citología, biopsia y colposcopia en cáncer cérvico uterino. Materiales y métodos: : Es un estudio, descriptivo, transversal y retrospectivo..Se realizó una revisión bibliográfica de los artículos publicados en los últimos 5 años, y de otros originales teniendo en cuenta su nivel de evidencia médica I - II. Se utilizaron los buscadores de la biblioteca Cochrane, Dynamed, Evidence-Based Medicine Updates, New England Journal of Medicine, J Clinical Oncology, Medscape, PubMed, PubMed Central y artículos de la Agencia Internacional del Cáncer de Francia. Se revisaron los siguientes aspectos: Definiciones, epidemiología, etiología, factores de riesgo, citología, colposcopia, histopatología, clasificaciones, estadios clínicos, tratamientos, prevención, promoción de salud y problemas sociales. Resultados: En Europa, se encontró una concordancia insignificante entre citología - colposcopia ( $k=0,16$; IC 95\% 0,09-0,22); una concordancia moderada entre colposcopia - biopsia ( $k=0,57$; IC 95\% 0,47-0,68); y una concordancia insignificante entre citología - biopsia ( $k=0,21$; IC 95\% 0,08-0,34). ; En América Latina; se observó: la citología S: $80 \%$ y E: $56.6 \%$; la colposcopia mostró S: $72,7 \%$ y E: $71,4 \%$. La colposcopia mostró mayor correlación diagnóstica que la citología cervical en lesiones pre malignas de cáncer cervico uterino. La relación colpo-histológica mostró un $87,5 \%$ de coincidencias en las LIE bajo grado y en las LIE de alto grado un 71,4\%. Perú 2017, citología mostró una S: $69 \%$ y E: $40 \%$; colposcopía S: $86 \%$ y E: $44 \%$. La relación citología - colposcopia S: $96 \%$ y E: $19 \%$. Existe una asociación estadísticamente significativa de los resultados de la anatomía patológica con los hallazgos colposcópicos y del PAP $(\mathrm{P}<0.05)$. La citología - colposcopia para lesiones precursoras y malignas de cáncer de cuello uterino moderada concordancia (Kappa: 0.4549); débil concordancia entre la citología - histología (Kappa: 0.3889) y buena concordancia entre la colposcopía histología (Kappa: 0.6191). Trabajos Regionales Los hallazgos anátomo-patológicos fueron: 25,9\% carcinomas invasivos y el 74,1\% lesiones intraepiteliales de alto de malignidad. Conclusiones: La citología y la colposcopía han demostrado tener una utilidad clínica para la detección precoz de displasia moderada, displasia severa, carcinoma in situ y carcinoma escamoso invasor. Aunque no se obtuvo una adecuada correlación colpo-citológica, la correlación cito-histológica fue muy elevada tanto en las lesiones intraepiteliales de bajo grado como en las de alto grado.

\section{Palabras clave: Cáncer de cérvix, Citología, Colposcopía, Biopsia}

\footnotetext{
ABSTRACT

Objective: To determine the relationship between cytology, biopsy and colposcopy in cervical cancer. Materials and methods: It is a descriptive, transversal and retrospective study. A bibliographic review of the articles published in the last 5 years, and of other originals taking into account their level of medical evidence I - II was made. We used search engines from the Cochrane library, Dynamed, Evidence-Based Medicine Updates, New England Journal of Medicine, J Clinical Oncology, Medscape, PubMed, PubMed Central and articles from the International Cancer Agency of France. The following aspects were reviewed: Definitions, epidemiology, etiology, risk factors, cytology, colposcopy, histopathology, classifications, clinical stages, treatments, prevention, health promotion and social problems Discussion: In Europe, insignificant concordance was found between cytology - colposcopy $(\mathrm{k}=0.16,95 \% \mathrm{Cl} 0.09-0.22)$; a moderate agreement between colposcopy - biopsy ( $\mathrm{k}=0.57,95 \% \mathrm{Cl} 0.47-0.68)$; and an insignificant concordance between
} 
cytology - biopsy ( $\mathrm{k}=0.21,95 \% \mathrm{Cl} 0.08-0.34)$. ; In Latin America; it was observed: cytology S: $80 \%$ and E: 56.6\%; colposcopy showed S: $72.7 \%$ and E: $71.4 \%$. Colposcopy showed a greater diagnostic correlation than cervical cytology in pre malignant lesions of uterine cervical cancer. The colpo-histological relationship showed $87.5 \%$ of coincidences in the low-grade IELs and $71.4 \%$ in the high-grade IELs. Peru 2017, cytology showed an S: $69 \%$ and E: $40 \%$; Colposcopy S: $86 \%$ and E: $44 \%$. The relationship cytology - colposcopy S: $96 \%$ and E: $19 \%$. There is a statistically significant association of the results of the pathological anatomy with the colposcopic and PAP findings $(P<0.05)$. Cytology colposcopy for precursor and malignant lesions of moderate cervical cancer concordance (Kappa: 0.4549); weak concordance between cytology - histology (Kappa: 0.3889) and good agreement between colposcopy - histology (Kappa: 0.6191). Regional Workings The anatomopathological findings were: $25.9 \%$ invasive carcinomas and $74.1 \%$ intraepithelial lesions of high of malignancy. Conclusions: Cytology and colposcopy have been shown to be clinically useful for the early detection of moderate dysplasia, severe dysplasia, carcinoma in situ, and invasive squamous cell carcinoma. Although an adequate colpo-cytological correlation was not obtained, the cyto-histological correlation was very high in both low-grade and high-grade intraepithelial lesions.

Keywords: Cervical Cancer, Cytology, Colposcopy, Biopsy

\section{INTRODUCCIÓN}

El cáncer del cuello uterino es una alteración celular que se origina en el epitelio del cuello del útero y que se manifiesta inicialmente a través de lesiones precursoras de lenta y progresiva evolución. Estas pueden suceder en etapas de displasia leve, moderada o severa, y pueden evolucionar a cáncer in situ y/o invasor cuando la lesión traspasa la membrana basal. Es la primera causa de muerte por cáncer en la población femenina, en los países en vía de desarrollo, y un problema importante de salud pública $(1,2)$.

Tiene un impacto negativo en la población femenina; el que es más frecuente en la de los países en vías de desarrollo (2).

¿Dónde se encuentran los problemas que no han permitido reducir al mínimo o eliminar toda la carga social que representa el cáncer del cuello uterino para cualquier país y en especial para los países pobres? .Desde que en 1941 Papanicolaou y Traut dieron a conocer la técnica de toma de la muestra y de coloración para los frotis de la citología exfoliativa de la vagina y el cuello uterino, y convertirse la prueba en un examen de tamizaje poblacional mucho se ha avanzado sobre el conocimiento del cáncer cervical (3).

El cribado de mujeres sanas, mediante citología cervical, ha demostrado su eficacia debido a la detección de lesiones pre-malignas asintomáticas cuyo tratamiento evita su progresión a carcinoma invasor (4).

La citología y la colposcopia se han utilizado a través de los años con el objetivo de diagnosticar las afecciones pre-malignas y malignas del cérvix uterino; sin embargo, el estudio histológico es el que resulta concluyente para poder establecer el diagnóstico definitivo, como una prueba de oro en la patología neoplásica cervical. Este puede realizarse por una biopsia en sacabocados; la conización con bisturí y la que se realiza con asa diatérmica, hoy por hoy, una técnica conservadora de la fertilidad que permite diagnosticar y tratar en el mismo momento $(5,6)$.

El presente trabajo tratará de la relación que existe entre citología, biopsia y colposcopia en cáncer cérvico uterino.

\section{DESARROLLO}

El cáncer del cuello uterino (CCU) es una enfermedad multifactorial, que se desarrolla generalmente en la zona de transformación de la unión escamo-columnar del cuello uterino, a partir de lesiones precursoras después que ha ocurrido una infección por el virus del papiloma humano, en presencia de otros cofactores: genéticos, ambientales, o no que se discutirán posteriormente (8). Se han descrito diversos tipos de CCU: entre los que predominan el escamoso, en sus diferentes variantes histológicas (90-95\%), y el adenocarcinoma cervical (< 5 $\%)$. Otros cánceres cervicales menos frecuentes son los sarcomas, y recientemente se ha descrito un melanoma maligno primario de cuello uterino (7).

La incidencia del carcinoma de células escamosas ha disminuido por la introducción de los programas de pesquisaje con el frotis cervical mediante la técnica de Papanicolaou en países con programas eficaces y bien estructurados. Este tipo de tumor maligno es mucho más frecuente que el de células pequeñas o que el adenocarcinoma cervical, en todo el mundo $(2,8)$. La incidencia anual por 100000 mujeres en EEUU reportada en el 2008, era de 6.6 para el escamoso; 1,2 para el adenocarcinoma y 0.06 para el carcinoma de células pequeñas (2).

La prevalencia mundial; el cáncer de cuello uterino es el cuarto cáncer más común en mujeres y el séptimo en general, con un estimado de 528,000 nuevos casos en 2012. Al igual que con el cáncer de hígado, una gran mayoría (alrededor del 85\%) de la carga mundial ocurre en las regiones menos desarrolladas, donde representa casi el $12 \%$ de todos los cánceres femeninos. Las regiones de alto riesgo, con una tasa de incidencia estandarizada por edad estimada de más de 30 por 100,000 mujeres, incluyen África Oriental (42.7), Melanesia (33.3), Sur de África (31.5) y África central(30.6). Las tasas son más bajas en Australia / Nueva Zelanda (5.5) y Asia occidental (4.4). El cáncer de cuello uterino sigue siendo el cáncer más común en las mujeres de África oriental y central (9).

Se estima que hubo 266,000 muertes por cáncer de cuello uterino en todo el mundo en 2012, lo que representa el $7,5 \%$ de todas las muertes por cáncer en mujeres. Casi nueve de cada diez (87\%) muertes por 
cáncer de cuello uterino ocurren en las regiones menos desarrolladas. La mortalidad varía 18 veces entre las diferentes regiones del mundo, con tasas que van desde menos de 2 por 100.000 en Asia occidental, Europa occidental y Australia / Nueva Zelanda a más de 20 por 100.000 en Melanesia (20.6), centro (22.2) y Este (27.6) África (10,11). Figura 1,2

\section{Figura 1}

\section{Incidencia estimada de cáncer de cuello uterino en todo el mundo en 2012}

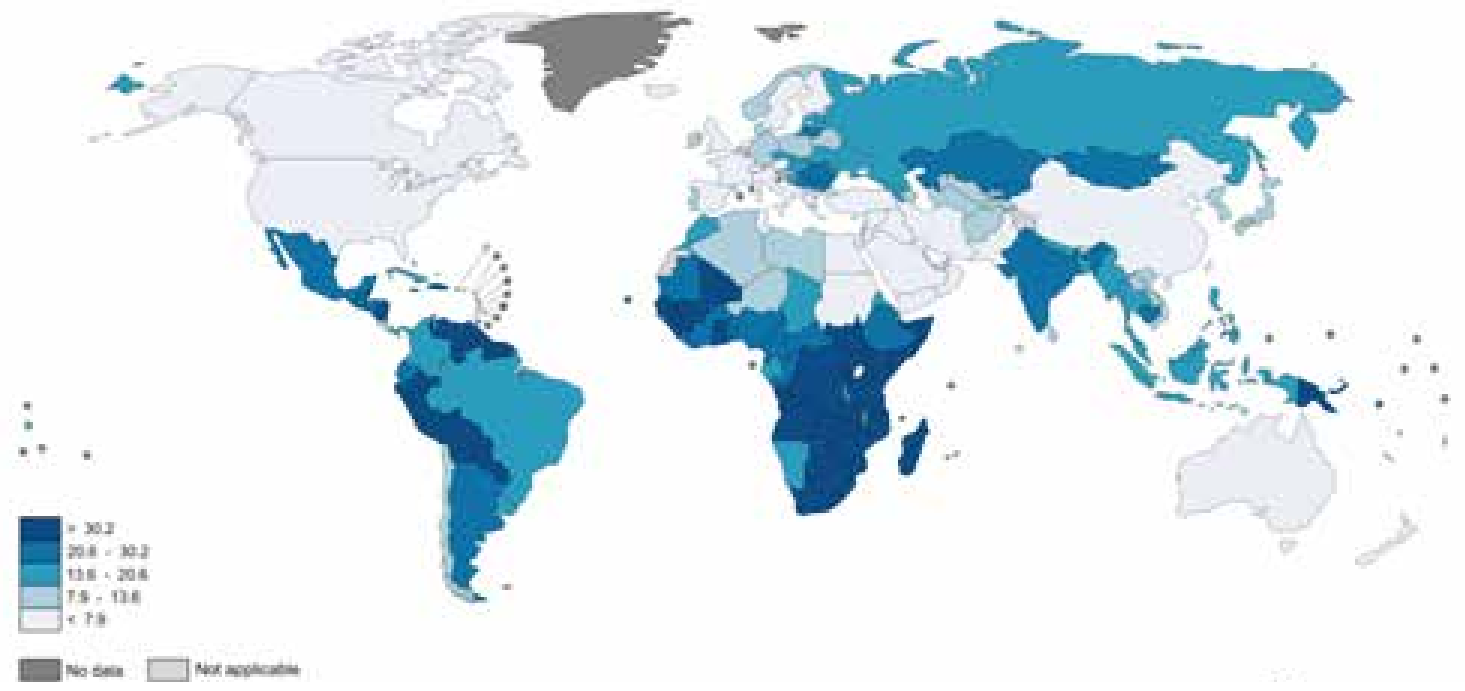

Tasas estandarizadas por edad estimadas (Mundo) por 100,000

GLOBOCAN 2012 (IARC) , Sección de Vigilancia del Cáncer (12/8/2018)

\section{Figura 2}

Estimación de la mortalidad por cáncer de cuello uterino en todo el mundo en 2012

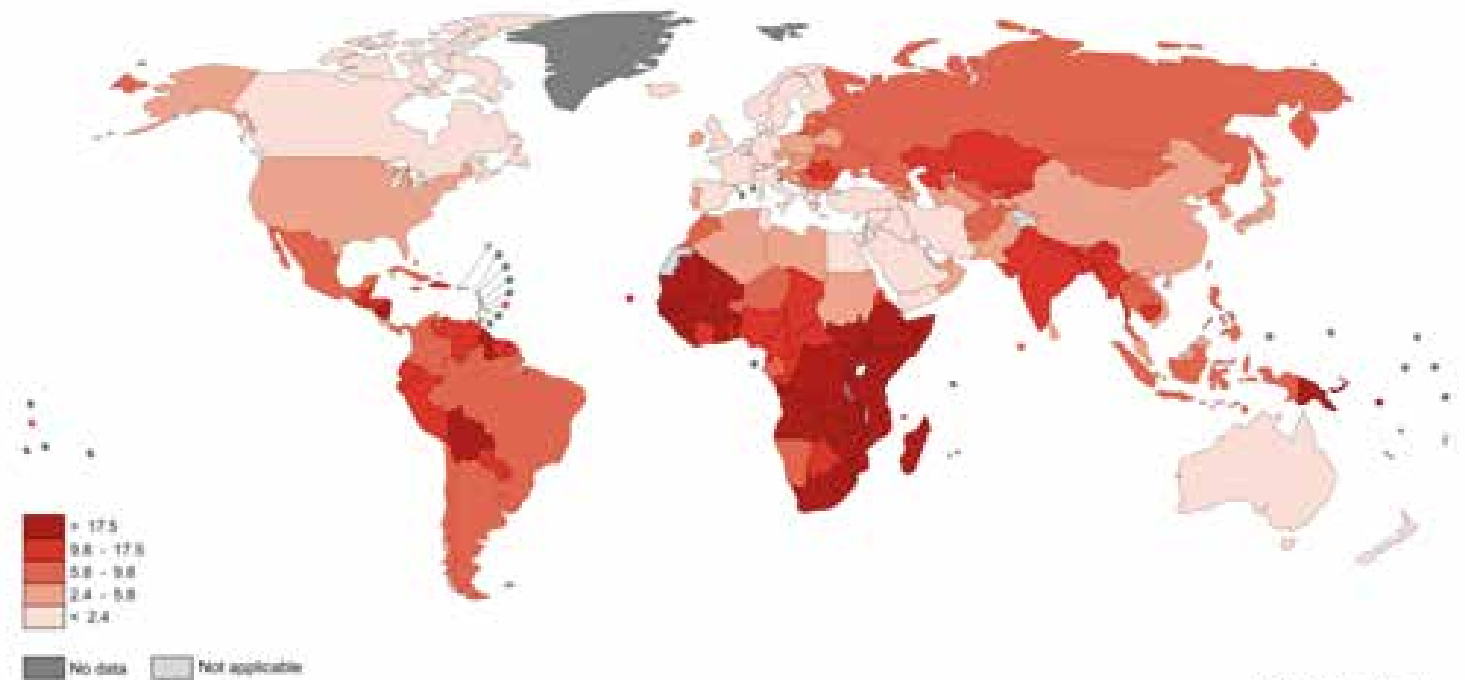

Tasas estandarizadas por edad estimadas (Mundo) por 100,000 GLOBOCAN 2012 (IARC), Sección de Vigilancia del Cáncer (12/8/2018) 
La Organización panamericana de la Salud (OPS) en el año 2012 informó que más de 83.000 mujeres fueron diagnosticadas de cáncer cervicouterino y casi 36.000 fallecieron por esta enfermedad en la Región de las Américas. Si se mantienen las tendencias actuales, el número de muertes en las Américas aumentará en un $45 \%$ en el 2030. Las tasas de mortalidad son 3 veces más altas en América Latina y el Caribe que en Norteamérica, evidenciando enormes desigualdades en salud. El tamizaje, seguido del tratamiento de las lesiones precancerosas identificadas, es una estrategia costo-efectiva de prevención. La vacunación contra el virus del papiloma humano (VPH) de mujeres adolescentes puede prevenir cerca del $70 \%$ de los casos de cáncer cervicouterino $(12,13)$.

Un metaanálisis estimó que la infección por VPH 16 ó 18 en el Perú está presente en el $6.6 \%$ de mujeres con citología normal, en el $27.3 \%$ de mujeres con lesiones cervicales de bajo grado, en el $53.1 \%$ de lesiones de alto grado y en el $65.9 \%$ de cáncer de cuello uterino. En pacientes referidas al Instituto Nacional de Enfermedades Neoplásicas - INEN entre el 2012-2014, los genotipos más frecuentes fueron 16 (23,8\%) y 6 (11,9\%). Un estudio de casos y controles en 198 mujeres con cáncer de cuello uterino en dos hospitales de Lima, encontró que los tipos más comunes de VPH fueron 16, $18,31,52$, y 35 (14).

La incidencia por cáncer de cérvix en el Perú es de 4446 casos por año (34,5 de 100000 habitantes) y la mortalidad de 2098 casos por año (16,3 de 100000 habitantes). Actualmente, en nuestro país, se ha difundido información acerca de las diferentes formas de prevención del cáncer de cérvix, Por ejemplo, la incorporación de la vacuna contra el virus del papiloma humano, nuevas pruebas moleculares para la detección del virus del papiloma humano, la difusión y masificación del Papanicolaou son parte de la prevención del cáncer de cérvix al favorecer el diagnóstico de esta patología en estadios tempranos $(15,16,17)$. Figura 3

\section{Figura 3}

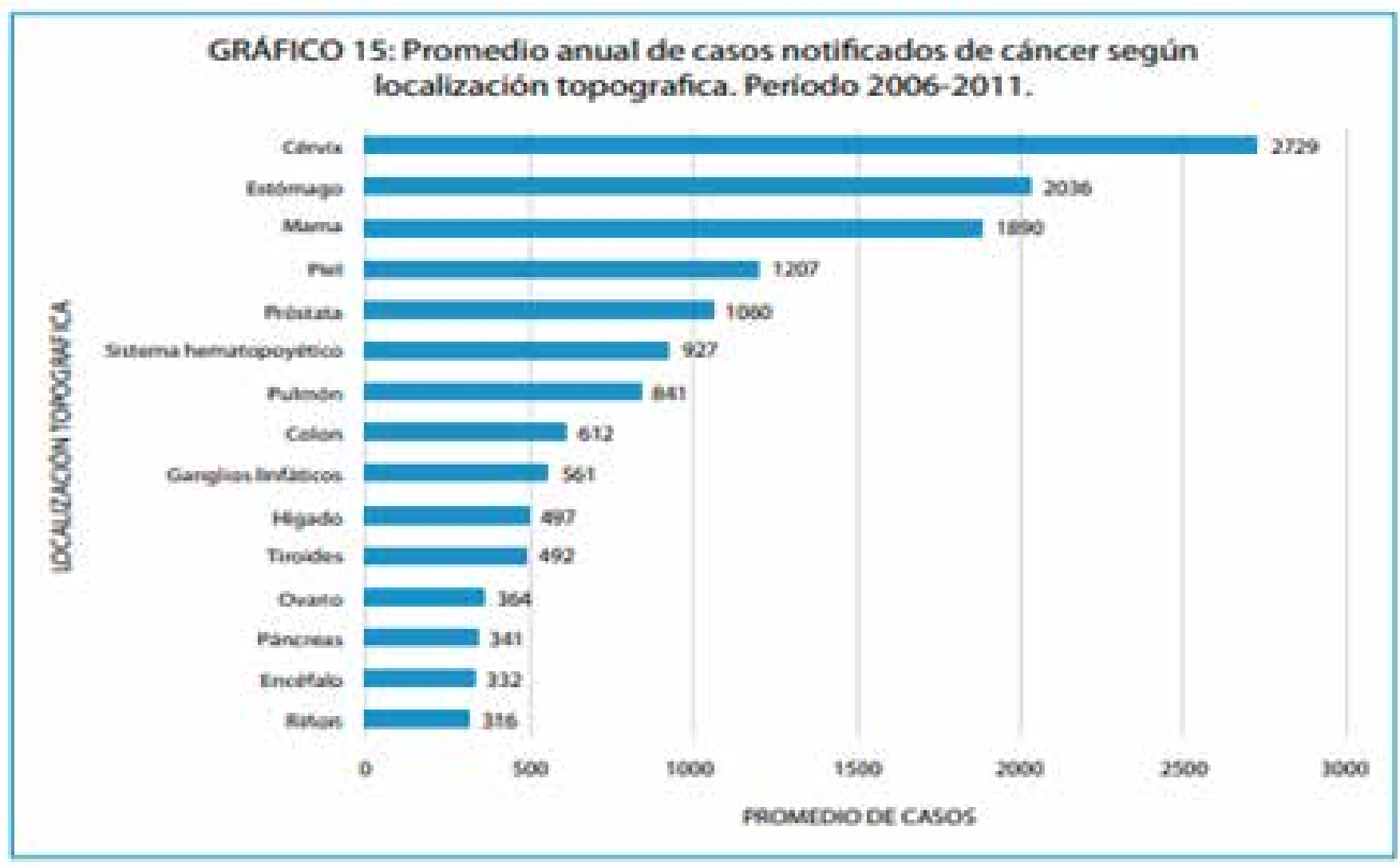

Fuente: Sistema Nacional de Vigilancia Epidemiologica. 
En el Perú, la neoplasia más frecuentemente diagnosticada entre mujeres procedentes de las diferentes regiones del país, es el cáncer de cuello uterino (24.9\%). Este se diagnostica, en su mayoría, en estados avanzados de la enfermedad. En la Región Ica, el cáncer cervical afecta a un número substancial de mujeres en edades reproductoras y laboralmente activas con acceso limitado a actividades de detección, diagnóstico precoz o tratamiento. Por ello, es necesario fortalecer la capacidad de diagnóstico y tratamiento de lesiones de la patología cervical tempranamente. "El mayor hincapié debe hacerse en las lesiones precancerosas", es la opinión que comparten y enfatizan los diferentes investigadores de la Organización Mundial de la Salud, dedicados a los aspectos epidemiológicos relacionados con el cáncer de cuello uterino (16).

En la Región Ica, según datos estadísticos de servicio de estadística e informática de la Dirección Regional de Salud de Ica, durante el periodo del 2015 se encontró el $15.52 \%$ de cáncer de cuello uterino, ocupando el primer lugar. En el Hospital Santa María del Socorro, el servicio de estadística e informática reportó una frecuencia de presentación del $12.81 \%$ de cáncer cervical. El incremento de casos de cáncer en lca puede ser explicado por determinantes sociales como la transición demográfica, epidemiológica, la pobreza que empeora el acceso a los servicios de salud, los cambios de dieta, los hábitos alimenticios. En los últimos dos años se viene trabajando desde el primer nivel de atención realizando la prevención primaria y en los hospitales la prevención secundaria $(16,17)$.

\section{Etiología y factores de riesgo}

El cáncer cérvico uterino va usualmente precedido por las lesiones precursoras, inclusive 10 años antes de presentarse el mismo (17). Se ha demostrado en un estudio de cohorte retrospectivo en 7564 mujeres que fueron seguidas por neoplasia intraepitelial cervical (NIC) durante 2 -29 años, que $0.3 \%$ desarrollaron cáncer invasor, una incidencia 3 veces más alta que lo que ocurre en la población general, sin haber tenido neoplasia intraepitelial cervical previa (18).

Por otra parte, se ha demostrado que casi todos los casos de cáncer cervical y de neoplasia intraepitelial cervical severa (NIC 3) son positivos al ADN viral del VPH, y que esa asociación incrementaba el riesgo de cáncer cervical, según un estudio de caso-control con 118 mujeres con cáncer invasor diagnosticado en promedio 5.6 años después del pesquisaje y en 118 controles con 2 citologías normales en el mismo período de tiempo. Ningún control tenía el ADN viral, pero todas las mujeres con cáncer sí lo presentaban (19) .Estudios posteriores con mayor nivel de evidencia respaldaron estos resultados (20).

Los factores de riesgo del cáncer cérvico uterino son tanto de condición biológica como de carácter psicosocial. La infección por VPH se adquiere sexualmente por más del $50 \%$ de todos los adultos sexualmente activos al menos una vez en su vida. En las mujeres norteamericanas se ha estimado una prevalencia de 26.8 \% (23.3 - 30.9 \%) . La población general alrededor del $10 \%$ de las mujeres han tenido infección por el VPH en un momento dado, y que el 70.3 $\%$ de los cánceres invasores del cuello uterino se atribuyen a los tipos VPH 16 y 18 (21).

Por otra parte, se ha comprobado que la infección aumenta en aquellas que tienen más parejas sexuales. Todo parece indicar entonces que el cáncer del cuello uterino es la consecuencia oncológica más común de la infección por el VPH, lo que puede conllevar a un cáncer invasor y eventualmente a producir la muerte de estas mujeres (21).

El tipo viral parece estar relacionado con uno u otro tipo de cáncer cervical. Mientras el HPV-16 está relacionado y es más prevalente en el tipo escamoso, el HPV-18 parece relacionarse más con el adenocarcinoma cervical, según un estudio de casos-controles (22), pero al parecer el HPV-18 tiene mayor poder oncogénico (23).

Es importante destacar que el VPH 16 puede sobrevivir en superficies secas inanimadas por más de 7 días y que ello podría constituir un bajo por ciento de transmisión no sexual del mismo (24).

Entre los posibles factores de riesgo se han mencionado: - La relación sexual: las mujeres inactivas sexualmente raramente desarrollan cáncer cervical, mientras la actividad sexual en edades tempranas, con múltiples parejas sexuales es un fuerte factor de riesgo (25).

- La pareja sexual masculina sin circuncidar con mayores posibilidades de infectarse con el VPH y trasmitirlo a las mujeres, ya que la mayoría de los compañeros sexuales de mujeres con NIC tenían infección por VPH (26).

- El uso a largo plazo de anticonceptivos hormonales, comparado con las mujeres que nunca los han usado, se observa mayor riesgo de CCU. Por otra parte, en aquellas que los han usado por menos de 5 años no hay incremento del riesgo; hecho aún no debidamente comprobado $(27,28)$.

- Paridad: este un factor largamente estudiado pero no estrechamente relacionado con el cáncer cervical (29).

- La exposición in útero al dietilestilbestrol ha mostrado incremento del riesgo del adenocarcinoma endocervical (27).

- La infección con VIH. Se ha comprobado que las mujeres seropositivas al VIH, tienen altas tasas de tipos de VPH oncogénicos y el que el cáncer invasor se presentaba en el $2.5 \%$ de las mujeres entre 20-49 años con SIDA en 15 países europeos (30).

- El tabaquismo por su poder inmunosupresor, y porque su asociación con la infección con el VPH se ha comprobado que aumenta el riesgo de padecer de cáncer cervical (31).

- Otros factores pueden actuar en la incidencia del cáncer cervical: el nivel de ingresos, las medidas de salud pública, el acceso y uso de los servicios de salud, el estado educacional, la percepción del riesgo a enfermar, la edad y la herencia han sido considerados por varios autores como de riesgo.

\section{Historia natural de la carcinogénesis cervical}

Actualmente hay evidencia contundente que indica que la infección por el virus de papiloma humano (VPH) es la causa del desarrollo del cáncer de cuello uterino. La 
mayoría de las mujeres que se infecta con el virus de papiloma humano superan la infección espontáneamente. Pero para un pequeño grupo de mujeres, esta infección persiste, progresa y se convierte en lesiones precancerosas que, si no se tratan, pueden convertirse cáncer de cuello uterino. La historia natural de la enfermedad revela la presencia de un fenómeno dinámico de progresión, persistencia y regresión de lesiones intraepiteliales en las cuales el virus papiloma humano juega un papel preponderante (32). Figura 4.

\section{Figura 4}
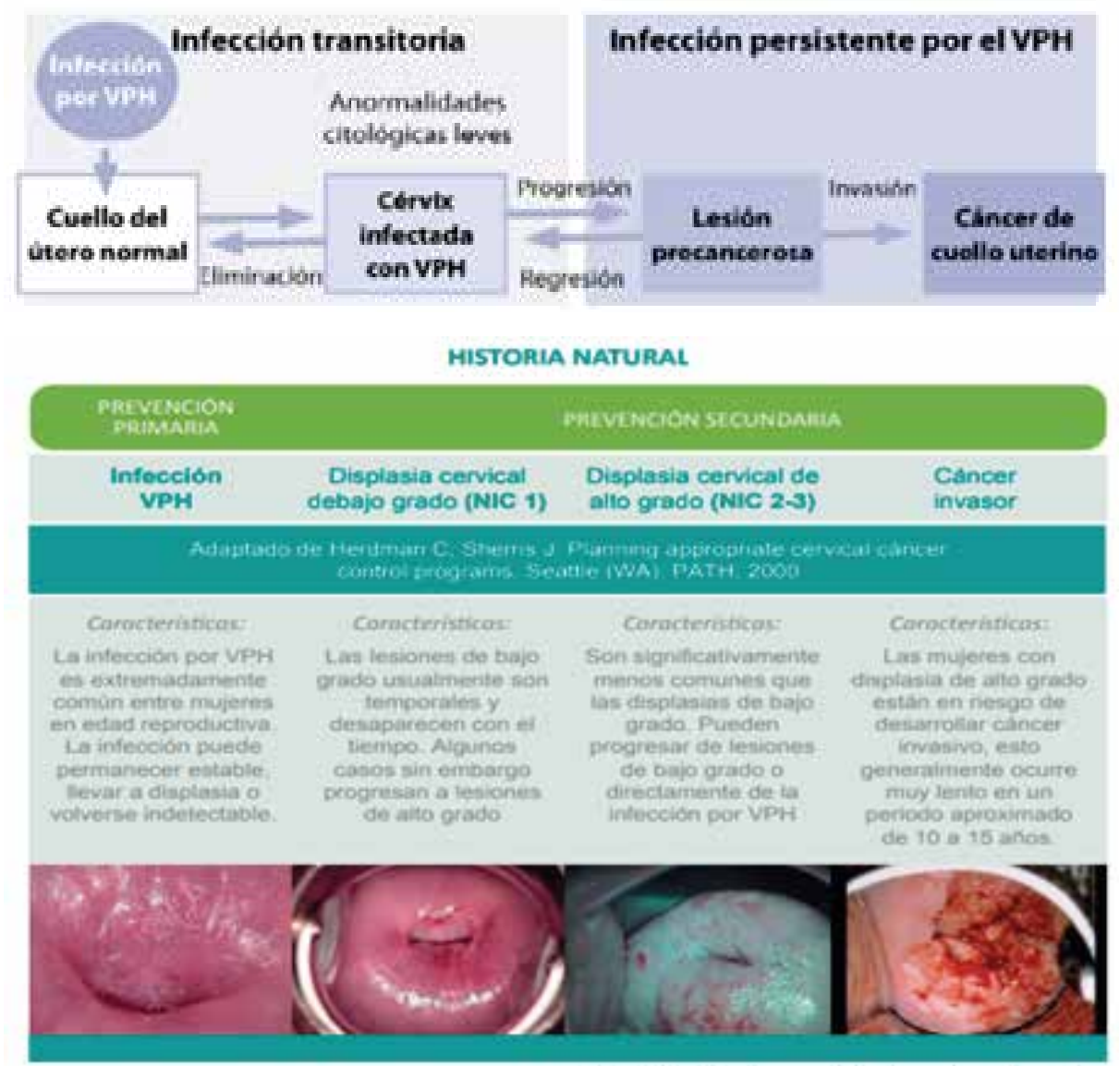

Fuente: Informe N027-2013 de la Dirección General de Epidemiología del MINSA

Después de producida la infección por el virus del papiloma humano en muchos casos se produce la regresión hacia la normalidad, es decir, la cura de la infección. En otros, cuando ya el genoma viral está integrado al de las células del epitelio escamoso cervical, entonces puede ocurrir la progresión hacia las lesiones intraepiteliales cervicales, y en los casos más severos a la invasión (33).

Inclusive en las mujeres muy jóvenes se observan lesiones intraepiteliales cervicales y esto puede deberse a los cambios en los estilos de vida, en tanto que las relaciones sexuales comienzan en edades más tempranas y es común el cambio de pareja (33).

La historia natural del cáncer cérvico uterino implica la progresión gradual por etapas intraepiteliales pre-invasoras (neoplasias intraepiteliales cervicales o intracervicales NIC I, NIC II, NIC III y carcinoma in situ, conocido por su sigla CIS) y carcinoma invasor en sus diferentes etapas. La neoplasia intraepitelial cervical se caracteriza por alteraciones de la maduración y anomalías nucleares Si la displasia está confinada al tercio inferior del epitelio estamos en presencia de una NIC I también conocida como lesión intraepitelial de bajo grado (LIE-BG); si implica los dos tercios inferiores se denomina NIC II y si las anomalías nucleares afectan a más de dos tercios de todo el espesor del epitelio están en presencia de una NIC III. Estas dos últimas denominaciones, en conjunto, se conocen también como: lesiones intraepiteliales de alto grado (LIE-AG), las cuales se han integrado en diferentes clasificaciones desde la propuesta por Papanicolaou hasta el actual Sistema Bethesda (34).

Con el transcurso de los años se han establecido diferentes clasificaciones diagnósticas para las lesiones intraepiteliales. Desde la inicial de Papanicolaou (2), que se concebía en grados de severidad: desde el grado I, que correspondía a la citología normal, hasta el grado V. En la actualidad, es muy aceptada la propuesta de Richard (1960) que clasifica a estas lesiones en neoplasia intraepitelial cervical y las divide a su vez por grado que 
van desde grado I hasta el III. Otro sistema de clasificación y de gran auge internacional y utilizado por la mayoría de los países es la clasificación surgida en 1988, en el estado de Maryland en Estados Unidos, conocida como Sistema Bethesda. Esta clasificación incorpora el término de Lesión intraepitelial escamosa de bajo grado, que incluye a las neoplasias intraepitelial cervical grado I (NIC I) y cambios producidos por el virus del papiloma humano; y la lesión intraepitelial escamosa de alto grado, que incluye al NIC II y NIC III y al carcinoma in situ (35). Figura 5

\section{Figura 5}

Cuadro comparativo de la Nomenclatura del Diagnóstico Citológico según el Sistema De Papanicolaou, Richard y el Sistema de Bethesda, Nota que el Consenso de Bethesda Las Lesiones de Alto Grado de Malignidad Incluyen a NIC II, III y al Carcinoma in Situ

\begin{tabular}{|c|c|c|}
\hline $\begin{array}{c}\text { Sistema de } \\
\text { Papanicolaou }\end{array}$ & $\begin{array}{c}\text { Sistema de } \\
\text { Richart }\end{array}$ & Sistema Bethesda \\
\hline Negativa (I) & Negativa & Negativa \\
\hline \multirow[t]{2}{*}{ II } & $\begin{array}{c}\text { Atipia escamosa } \\
\text { reactiva o imposible } \\
\text { de clasificar }\end{array}$ & ASCUS- $\mathrm{ASCH}$ \\
\hline & Infección por VPH & \multirow[b]{2}{*}{$\begin{array}{c}\text { Lesiones } \\
\text { intraepiteliales de bajo } \\
\text { grado de malignidad }\end{array}$} \\
\hline III & $\begin{array}{c}\text { Neoplasia } \\
\text { intraepitelial cervical } \\
\text { Grado I (NIC I) }\end{array}$ & \\
\hline III & $\begin{array}{c}\text { Neoplasia } \\
\text { intraepitelial cervical } \\
\text { Grado II (NIC II) }\end{array}$ & \multirow{2}{*}{$\begin{array}{l}\text { Lesiones } \\
\text { intraepiteliales de alto } \\
\text { grado de malignidad }\end{array}$} \\
\hline III & $\begin{array}{c}\text { Neoplasia } \\
\text { intraepitelial cervical } \\
\text { Grado III (NIC III) }\end{array}$ & \\
\hline IV & \multicolumn{2}{|c|}{ Carcinoma in situ } \\
\hline v & Căncer escamoso in & asor del cuello uterino \\
\hline
\end{tabular}

Fuente: Atlas de Citología de la IARC

La conversión desde un NIC I a un cáncer invasor es poco probable, pero la de un NIC III incrementa su riesgo relativo, lo que implica la presencia de lesiones previas en el cuello del útero antes de llegar al cáncer invasor por un lado, y por el otro que mientras más severas son las lesiones más probabilidad de tener un cáncer invasor del cuello uterino, si se dejan sin tratar. Las neoplasias intraepiteliales cervicales son más comunes en las jóvenes, mientras el cáncer invasor ocurre en edades más altas (36).

La persistencia de la infección viral está relacionada con la presencia de lesiones intraepiteliales y la progresión hacia la malignización y se ha comprobado que la carga viral incrementa el riesgo del carcinoma in situ. La infección con VPH se asocia con riesgo aumentado de displasias de alto grado, especialmente dentro del año de la infección según un estudio prospectivo de 3 años de duración en 1075 mujeres que eran citológicamente normales y VPH negativas al momento del comienzo del estudio $44 \%$ de las mismas desarrolló la infección, y más comúnmente con el tipo 16, pero el 26 \% tenía múltiples tipos de VPH. 28 mujeres progresaron a NIC de alto grado, y si la infección es persistente, específicamente con los tipos 16 y 18 hay riesgo aumentado de lesiones intraepiteliales escamosas (37).
A finales de los años 60, y posteriormente en el 2001, en la reunión de Bethesda se brindaron nuevas consideraciones para la clasificación de la citología orgánica del cuello uterino, y así surge el concepto de alteraciones escamosas de significación dudosa (ASCUS) (28) y luego también el de alteraciones de células glandulares de significación dudosa (AGUS) (36).

Diagnóstico: Citología, Colposcopia e Histopatología El método de cribado citológico en el cuello uterino es uno de los capítulos más fructíferos de la medicina moderna. Por medio de la prueba de Papanicolaou se detectan casi todas las neoplasias cérvico uterinas durante las fases pre-maligna o maligna oculta temprana típicamente duraderas, lapso en que los resultados del tratamiento son óptimos. Sin embargo, países que poseen programas de detección organizada siempre se han percatado de una disminución impresionante entre 60 y $70 \%$, en la incidencia del cáncer cérvico uterino y los índices de mortalidad (38).

El diagnóstico citológico se basa en la técnica de Papanicolaou y Traut (1941) que tiene en cuenta las propiedades de las células de epitelio del cuello uterino, y las características nucleares y citoplasmáticas. Permite diagnosticar las lesiones inespecíficas, específicas 
infecciosas por Trichomonas, Chlamydias, Herpes Virus, VPH y otras, así como las restaurativas, y las neoplasias intraepiteliales cervicales en sus diferentes grados, descritos previamente.

Es bueno recordar que no es una prueba diagnóstica de certeza, y tiene por tanto falsos negativos y falsos positivos. La sensibilidad de esta prueba es de $60 \%$, con variabilidad entre $29-80 \%$ en diferentes laboratorios del mundo y para diferentes edades (39).

El propósito y logro de esta prueba es pesquisar todas las lesiones intraepiteliales antes de que progresen a enfermedad invasora. Es cierto que ha permitido reducir la incidencia del cáncer invasor, pero no se espera que detecte todas las lesiones precursoras y no es apropiada para detectar neoplasias invasoras (40).

Se han diseñado varios aditamentos para obtener mejores resultados con la prueba citológica: diferentes espátulas, citología en base líquida, se cambian las frecuencias de pesquisaje (40). Se han diseñado diversas estrategias para aumentar el rendimiento de esta prueba, sin lograrse un efecto total globalizador y se ha señalado que el pesquisaje en mujeres de 20-24 años tiene poco o ningún impacto en las tasas de incidencia de cáncer invasor del cuello uterino $(41,42)$.

Entre las razones para que no se logre impacto por el programa se señalan, los errores de muestreo que incrementan la proporción de falsos negativos, frotis no adecuados totalmente por la presencia de leucocitos, sangre, presencia de patógenos vaginales, el lugar de la toma de la muestra, las relaciones sexuales practicadas la noche anterior a la toma de la muestra, el uso de duchas vaginales, el uso de tabletas vaginales, que pueden entorpecer el diagnóstico o esconder células afectadas no bien visibles al microscopio óptico (43).

La cobertura es un aspecto relevante. Se conoce que la mayoría de las mujeres que padecen de cáncer invasor del cuello uterino, nunca se han pesquisado, o el mismo se hace no sistemáticamente (44).

La edad de comienzo es variable, se ha demostrado que el comienzo del pesquisaje por debajo de los 25 años, da poco resultados, en tanto que el cáncer cervical a estas edades es sumamente raro, aunque se detectan numerosas lesiones de bajo grado de malignidad, que como se sabe pueden regresar espontáneamente (44). En las mujeres jóvenes se ha visto un incremento del adenocarcinoma cervical. No hay que olvidar que desde la infección por el VPH hasta la aparición del cáncer cervical pueden pasar hasta 10-15-20 años (45). Es necesario tener en cuenta los factores de riesgo para incrementar el pesquisaje en las mujeres con alto riesgo de padecer de infección por VPH o de tener un cáncer cervical (40).

En el mundo no existen evidencias para un punto de corte de cuando terminar el pesquisaje masivo, en tanto que ellas poseen poca carga viral y el significado de la citología a estas edades no es nada sensible (45).Por tanto, no se pesquisarán aquellas mujeres que no han tenido relaciones sexuales, o que hayan sido histerectomizadas por causas benignas (43).

\section{Intervalos}

Mediante modelaje computarizado se ha detectado que la mejor estrategia es el pesquisaje cada 6 meses con dos pruebas, en tamizaje anual. Sin embargo, la escuela Americana de Obstetras y Ginecólogos plantea el pesquisaje anual, comenzando 3 años después de la iniciación de la actividad sexual o a los 21 años. Cada 2-3 años después de 3 pruebas consecutivas negativas en mujeres mayores de 30 años sin historia de NIC II o III, inmunosupresión, infección por $\mathrm{VIH}$ o exposición in útero de dietilestilbestrol. Para las mujeres mayores de 30 años la prueba anual es una opción. Si la combinación de la prueba con la detección del ADN de VPH da negativa, entonces el reexamen se debe hacer nunca antes de los tres años (44).

En Perú el enfoque de "TAMIZAJE y TRATAMIENTO" o "VER Y TRATAR", la decisión sobre el tratamiento se basa en una prueba de tamizaje, y el tratamiento se dispensa con prontitud o, idealmente, de inmediato tras una prueba de tamizaje positiva. En las mujeres con resultados negativos en la prueba de IVAA o en el PAP, el nuevo tamizaje deberá realizarse en tres años. En las mujeres con resultados negativos en la prueba de tamizaje de VPH, se debe proceder a un nuevo tamizaje tras un intervalo mínimo de cinco años (45). Figura 6 


\section{Figura 6}

Tamizaje de cáncer de cuello de útero en mujeres de 30 a 49 años

Con Prueba Molecular para VPH (PM VPH)

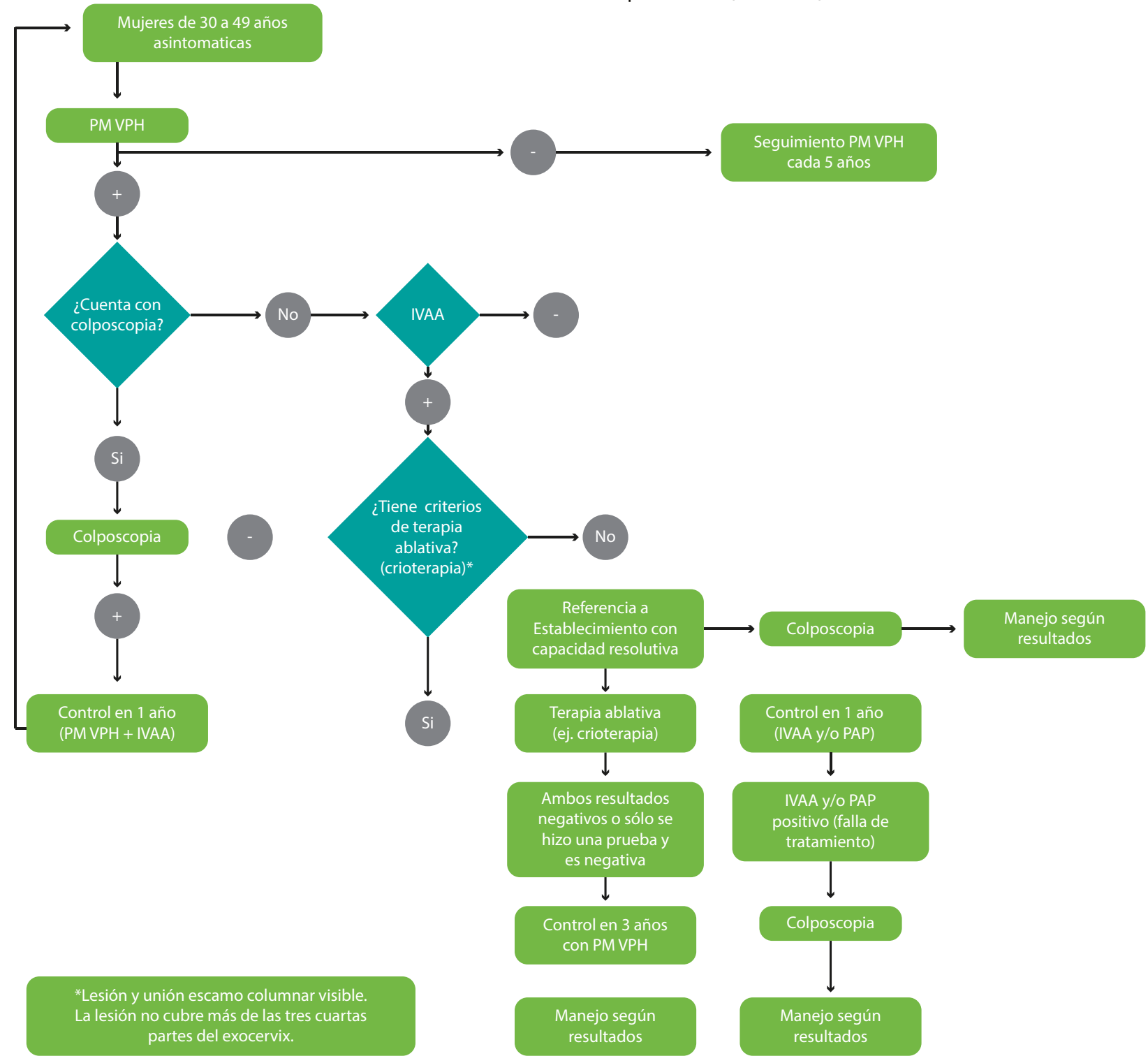

Fuente: Informe N027-2013 de la Dirección General de Epidemiología del MINSA

Basado en un estudio de 286 mujeres con cáncer cervicouterino de 18 años con cánceres estudió la historia citológica previa y se encontró que la mayoría tuvo citología negativa 6 años antes del diagnóstico, y 73 mujeres nunca fueron pesquisadas (46).

Es decir, la sensibilidad y la especificidad de la prueba son variables y dependerá de varios factores, entre los que se encuentran la preparación de la mujer para la realización de la misma, la calidad de la toma de la muestra citológica, el lugar de la toma (que debe incluir siempre material de la zona de transformación escamo-columnar), el extendido, la fijación y la tinción, así como del entrenamiento de los citotecnólogos. Por todo lo anterior se hace necesaria una auditoría permanente del programa de pesquisaje en todos sus componentes.

\section{Diagnóstico por Colposcopia}

Desde los comienzos ha habido progresos en el diagnóstico colposcópico. La utilización del ácido acético al $5 \%$ y visión bajo colposcopio (microscopio estereoscópico) y el índice de Reid (47), permiten detectar lesiones que se han categorizado en negativas y positivas y no satisfactorias. Sirve también este procedimiento para corroborar de una inspección visual con ácido acético al $5 \%$ (IVA) (48). Es útil también cuando existen resultados citológicos no útiles repetidos, y para realizar biopsias dirigidas (49).

Con este procedimiento el epitelio anormal (displásico) se torna blanco y puede ser detectado fácilmente. La sensibilidad del IVAA varía de acuerdo al entrenamiento y práctica y se ha encontrado entre el $70 \%$ al $80 \%$ para detectar NIC 2 y lesiones más severas (16). 
Entre los resultados anormales o positivos se citan la lesión aceto blanca que puede variar en intensidad y tiempo de tinción en dependencia de la cantidad de proteínas (generalmente anómalas) acumuladas en el epitelio, el punteado, el mosaico y la presencia de vasos atípicos, entre otras (50). Al momento de realizar la colposcopia es importante tener en cuenta la edad y si hay presencia o no de embarazo (45) Como la colposcopia tiene resultados variables en sensibilidad y especificidad, y por supuesto, este es un hecho a afrontar, la auditoría de las colposcopias es también obligatoria para lograr mejor rendimiento del programa de pesquisaje de lesiones cervicales. Figura 7

\section{Figura 7}

Terminología Colposcópica del Cuello Uterino

\begin{tabular}{|c|c|c|c|c|}
\hline \multicolumn{2}{|c|}{ EVALUACION GENERAL } & \multicolumn{3}{|c|}{$\begin{array}{l}\text { - Adecuadalinadecuada a causa de ...(por ej.; } \\
\text { cuello uterino no claro por inflamacion, } \\
\text { sangrado, cicatriz) } \\
\text { Visibilidad de la unión escamocolumnar: } \\
\text { completamonte visible, parcialmento visible, no } \\
\text { visible. } \\
\text { Tipos de zona de transformación 1,2,3 }\end{array}$} \\
\hline \multicolumn{2}{|c|}{$\begin{array}{l}\text { HALLAZGOS COLPOSCOPICOS } \\
\text { NORMALES }\end{array}$} & \multicolumn{3}{|c|}{$\begin{array}{l}\text { Epitelio escamoso original: } \\
\text { * Maduro } \\
\text { Epitolio columnar } \\
\text { Epitelio escamoso metaplásico } \\
\text { * Quistes de Naboth } \\
\text { * Aberturas glandulares y/o criptas } \\
\text { Deciduosis on ol embarazo }\end{array}$} \\
\hline \multirow[t]{4}{*}{$\begin{array}{l}\text { HALLAZGOS } \\
\text { COLPOSCOPICOS } \\
\text { ANORMALES }\end{array}$} & $\begin{array}{l}\text { Principlos } \\
\text { generales }\end{array}$ & \multicolumn{3}{|c|}{$\begin{array}{l}\text { Ubicación de la lesion: dentro o fuera de la zona de } \\
\text { Transformación, ubicacion de la lesión según las } \\
\text { agujas del reloj. } \\
\text { Tamano de la lesión Nümero de cuadrantes del } \\
\text { cuello uterino que cubre la lesión, tamaño de la } \\
\text { lesion en porcentajes del cuello uterino. }\end{array}$} \\
\hline & $\begin{array}{l}\text { Grado } 1 \\
\text { (Menor) }\end{array}$ & $\begin{array}{l}\text { Epitelio acetoblanco } \\
\text { delgado. } \\
\text { Borde irregular }\end{array}$ & \multicolumn{2}{|c|}{$\begin{array}{l}\text { Mosaico fino, Puntillado } \\
\text { fino }\end{array}$} \\
\hline & $\begin{array}{l}\text { Grado } 2 \\
\text { (Mayor) }\end{array}$ & $\begin{array}{l}\text { Epitelio acetoblanco } \\
\text { donso, Aparicion } \\
\text { rapida de epitelio } \\
\text { acetoblanco. } \\
\text { Orificios glandulares } \\
\text { abiertos con bordes } \\
\text { engrosados. }\end{array}$ & \multicolumn{2}{|c|}{$\begin{array}{l}\text { Mosaico grueso, Puntillado } \\
\text { grueso. } \\
\text { Bordes delimitados, } \\
\text { Signo del limite del borde } \\
\text { interno, } \\
\text { Signo de cresta o } \\
\text { sobreelevado. }\end{array}$} \\
\hline & $\begin{array}{l}\text { No } \\
\text { especificos }\end{array}$ & \multicolumn{3}{|c|}{$\begin{array}{l}\text { Leucoplasia (queratosis, hiperqueratosis), Erosión } \\
\text { Solución de Lugol (Test de Schiller): } \\
\text { positivo/negativo }\end{array}$} \\
\hline \multicolumn{2}{|c|}{ SOSPECHA DE INVASION } & \multicolumn{3}{|c|}{$\begin{array}{l}\text { Vasos atiplcos } \\
\text { Signos adicionales: Vasos delgados, superficie } \\
\text { irregular, lesión exofitica, necrosis, ulceración } \\
\text { (necrotica), tumoración nodular. }\end{array}$} \\
\hline \multicolumn{2}{|c|}{ HALLAZGOS VARIOS } & \multicolumn{2}{|c|}{$\begin{array}{l}\text { Zona de transformación } \\
\text { congenita, } \\
\text { Condiloma. } \\
\text { Pollipo (exocervical } \\
\text { fendocervical) } \\
\text { Inflamacion, }\end{array}$} & $\begin{array}{l}\text { Estenosis, } \\
\text { Anomalia congénita, } \\
\text { Anomalias post } \\
\text { tratamiento, } \\
\text { Endometriosis }\end{array}$ \\
\hline
\end{tabular}

\section{Diagnóstico por Biopsia}

Se pueden usar varios tipos de biopsias para diagnosticar los cánceres o los pre-cánceres de cérvix. Si la biopsia puede extirpar completamente todo el tejido anormal, éste puede que sea el único tratamiento necesario (51).

En cuanto al resultado histopatológico, puede revisarse la clasificación de la IARC (2007) (52). El resultado de la biopsia no solamente permite un diagnóstico preciso, sino que también permite evaluar los resultados de la citología y la colposcopia.

Para poder llegar a este diagnóstico, se debe emplear el examen histopatológico del tejido, que debe ser obtenido por biopsia, la cual en primera instancia puede ser guiada por colposcopía. En este paso inclusive se puede aplicar tratamiento si, por ejemplo, se detectara una lesión premaligna con el colposcopio. En este caso, se podría aplicar crioterapia en la lesión (luego de la biopsia) o emplear la escisión electroquirúrgica con asa (LEEP). Respecto a esto, hay evidencia de que los mejores métodos para tratar lesiones de bajo grado son los ablativos y para las lesiones de alto grado, los escisionales. Los métodos escisionales se pueden agrupar como la llamada conización cervical, dentro de la cual tenemos las siguientes formas: fría o quirúrgica, LEEP o radiofrecuencia y láser. Actualmente la conización cervical se considera el tratamiento de elección de las lesiones intraepiteliales de alto grado o NIC III (53). 


\section{Lesiones precursoras. Neoplasias intraepiteliales cervicales}

Las neoplasias intraepiteliales cervicales son las lesiones consideradas como la antesala del cáncer cervicouterino (54). El pronóstico de las neoplasias intraepiteliales cervicales es variable. Pueden regresar, persistir o progresar a estadios más severos. Así el carcinoma in situ puede persistir durante 3-10 años para luego hacerse invasor, pero en estudio de seguimiento en jóvenes se encontró que después de 36 meses, $62 \%$ de las lesiones había regresado, mientras $31 \%$ tenían displasia progresiva. En la cohorte de jóvenes con lesiones de alto grado se encontró regresión en $21.8 \%$, y a los 36 meses se encontró progresión a lesiones NIC 3 en el $31 \%$ de las adolescentes (55).

Después del tratamiento mediante escisión quirúrgica, la presencia de márgenes afectados no aumenta la tasa de error del procedimiento quirúrgico empleado, pero cuando la lesión es consistente con infección por VPH la tasa de fallo es del $8 \%$ (48).

En las mujeres mayores de 50 años, la persistencia o la recurrencia de las lesiones es mayor 3 veces, y en dependencia de las lesiones observadas, se realiza legrado endocervical o ponches de los cuatro cuadrantes del cuello uterino, lo que puede producir variaciones en el diagnóstico (56).

El tratamiento de las NIC se basa en la escisión de la lesión, mediante observación y seguimiento adecuado, especialmente para las lesiones de bajo grado. Si la lesión es de alto grado, entonces se usa la escisión o la ablación, o si hay preocupación de que la paciente se pierda del seguimiento.

La escisión se puede realizar por la conización, a través de cuchilla fría, asa diatérmica o aguja, o láser. Ninguna de las técnicas se ha encontrado que es superior a la otra, pero hay que tener algunas consideraciones relativas al procedimiento en la radiocirugía, como es el control del sangrado (57). La terapia ablativa requiere de una colposcopia satisfactoria, legrado endocervical negativo y ninguna sospecha de cáncer. Se realiza con láser, electrocauterio o crioterapia.

Se han empleado algunos medicamentos pero ninguno ha tenido evidencia consistente que sugiera efecto sobre la promoción de la regresión de las NIC. Entre ellos, destacan el interferón beta intramuscular, o intralesional, o en ambos, pero tiene muchos efectos adversos. Así se tiene a los retinoides que en 5 ensayos no parecen tener efecto alguno, betacarotenos orales durante 2 años o la vitamina $C$, no tienen efecto en mujeres con atipia menor o NIC 1, el ácido fólico, la difluorometilornitina por 28 días, la terapia fotodinámica con ácido 5 aminolevulínico entre otros (40). Hay que resaltar que muchas veces existe infección múltiple por el virus del papiloma humano y por tanto los tratamientos son incompletos. Después de establecido el diagnóstico de la biopsia y que el resultado fue de cáncer, entonces, realizar los estudios para determinar el estadio clínico y utilizar la clasificación TNM de la IARC, y otros estudios, entre los que se incluyen los de imágenes (58). La sobrevida dependerá, entre otros factores, del grado y el volumen del tumor, su variedad histológica y diferenciación, la edad de las pacientes y el tratamiento utilizado. Otro problema es la determinación del estadio clínico que tiene solamente una exactitud de un 30 \% (59).

\section{El tratamiento dependerá del estadio}

Mientras un carcinoma in situ puede resolver con tratamiento quirúrgico, el cáncer en estadio IA debe llevar una histerectomía total abdominal, y se ha propuesto además radiación intracavitaria, con un $100 \%$ del control del tumor. En el subgrupo IA1, con invasión de menos de $3 \mathrm{~mm}$, sin toma linfática ni vascular, se recomienda la histerectomía total vaginal, pero si el pronóstico es peor, entonces histerectomía radical y linfadenectomía pélvica. En los estadios IB, IIA, IVA, se ha investigado la cirugía radical vs. la radioterapia. El tratamiento específico para cada estadio clínico no será objeto de este trabajo, ya que hay múltiples publicaciones que lo evalúan, y en todo caso se siguen las guías clínicas de cada país. Más recientemente se está empleando el tratamiento con vacunas anti ADN viral, con resultados promisorios (60).

\section{Prevención de las neoplasias intraepiteliales cervical y del cáncer del cuello uterino}

La prevención primaria del cáncer cervical estaría dada por la evitación de la infección con el VPH, mediante las vacunas profilácticas (54), el uso de barreras para evitar que el virus infecte el cuello uterino: el condón, por ejemplo. - Las Vacunas:

-Existen tres tipos de vacunas contra el virus papiloma humano (VPH): La tetravalente y la bivalente que son altamente efectivas para prevenir infecciones por los tipos de VPH16, VPH18, que causan la mayoría de los canceres cervicales. La vacuna tetravalente también protege contra VPH6, VPH11 que se asocian a verrugas genitales. La tercera vacuna es la nonavalente que incluye protección contra VPH 6, 11, 16, 18, 31, 33, 45, 52, y 58 , pero aún no se encuentra disponible en el mercado. La prevención secundaria estaría dada por el pesquisaje mediante citología, o mediante el uso de la detección del tipo y de la persistencia viral. Se han diseñado varias pruebas que difieren en su sensibilidad, especificidad, valores predictores, y complejidad técnica. Entre ellas: inmunoperoxidasa, la hibridización in situ con fluoresceína $(\mathrm{FISH})$, el southern blot, la reacción en cadena de polimerasa (PCR) y la prueba de captura híbrida que no solamente mida la carga viral sino que detecta y diferencia entre virus oncogénicos y no oncogénicos $(61,62)$. La inspección visual en la Atención Primaria de Salud (APS) con ácido acético al 3-5 \% y solución yodo-yodurada de Lugol permite detectar lesiones ocultas al ojo desnudo (61), y que incrementan el rendimiento del pesquisaje, al detectar las lesiones en las mujeres con citología negativa, y que deben ser luego comprobadas mediante colposcopia. Ya en Pinar del Río se ha probado esta técnica con excelentes resultados (62).

La combinación de la prueba de detección de ADN viral y la inspección visual puede ser más costo-efectiva que el pesquisaje basado solo en la citología, según se ha demostrado en mujeres surafricanas (62). 


\section{Carga social y económica del cáncer del cuello uterino}

El cáncer cervical es un importante problema de salud, sobre todo en los países en desarrollo, donde en muchas mujeres se presentan en estadios avanzados de la enfermedad con bajas tasas de curación. Además de la citología, la prueba de inspección visual con ácido acético y en última instancia, la detección del ADN viral como una técnica de pesquisaje son las pruebas más deseables (61).

El tratamiento del cáncer cervical en los países en desarrollo es altamente dependiente de los recursos y la experiencia disponibles, y son muy caros ambos, lo que

\section{REFERENCIAS BIBLIOGRÁFICAS}

1. Carrascal M, Chávez C, Sesin F. Correlación diagnóstica de la citología cervical versus colposcopia en lesiones pre-malignas de cáncer cérvico-uterino. IPS Universitaria Barranquilla 2013. Revista Biociencias. Colombia 2014; 9(1): 37-44.

2. Ferlay J, Gray F, Pisani P, Parkin DM. Cancer incidence, Mortality and Prevalence Worldwide. CA Cancer J Clin. 2005 [Citado 12 de Julio de 2010]; 55(2). Disponible en:

http://onlinelibrary.wiley.com/doi/10.3322/canjclin.55 .2.74/pdf.

3. Papanicolaou GN, Traut HF. The diagnosis value of vaginal smears in carcinoma of the uterus. Arch Pathol Lab Med. 1997 [Citado 12 de Julio de 2010]. Disponible en:

http://www.ncbi.nlm.nih.gov/pubmed/9111103.

4. Lafalla O, García R, Gascón E, Laguna M, Abad C, Carazo $B$, et al. Comparación entre las técnicas de cribado de patología cervical y las conizaciones de tres Hospitales en España. Revista Chilena de Obstetricia y Ginecología. Chile 2017; 82(3): 265-270.

5. Rojas $O$, Alvarez $Z$, Avilés LY, Fernández $Y$, Sánchez MR. Correlación cito-colpo-histológica en pacientes atendidas en consulta de patología benigna de cuello. Revista de la sociedad cubana de enfermería. Cuba 2016; 23(2): 12-17.

6. Rivas EE. Biopsia de cérvix: Serie de casos. Revista de Salud Uninorte, Barranquilla. Colombia 2013; 29(2): 260-269.

7. Yücesoy G, Kus E, Cakiroglu Y, Muezzinoglu B, Yildiz K, Yuceoy I. Primary malignant melanoma of the cervix. Report of a case. Archives of Gynecology \& Obstetrics. ]. 2009 [Citado 26 de febrero de 2010]; 279(4). Available from:

http://www.springerlink.com/content/x280x772g4724 $807 /$.

8. Chen J. Small Cell Cervical Cancer Usually Has Poor Prognosis. Obstet Gynecol. 2008 [Citado 14 de agosto de 2010]; 111(6). Available from:

http://www.medscape.com/viewarticle/576728_print.

9. Fuentes: GLOBOCAN 2012 (IARC), disponible en http://globocan.iarc.fr/. The World Bank Group 2014 Indicators; available from:

http://data.worldbank.org/indicator/NY.GDP.PCAP.C D produce una carga adicional, no solamente a las mujeres si no a los estados que tratan de solucionar el problema con programas sociales de atención. La prevención siempre será más barata que el tratamiento de un solo caso de cáncer. Es importante señalar que además de la carga económica y social que presuponen los costos de los programas y de los tratamientos, existe también una carga psicológica que no debe obviarse.

Decirle a una mujer que es portadora del virus del papiloma humano y que puede desarrollar un cáncer, produce también una carga de ansiedad y stress, así como problemas familiares (63).

10. GLOBOCAN Cancer Fact Sheets: Cervical cancer globocan.iarc.fr/old/FactSheets/cancers/cervix-new. asp. Estimated Incidence, Mortality and Prevalence Worldwide in 2012.

11. Epidemiología del Cáncer de Cuello en América Latina Luis G. Capote Negrin . Cirujano Oncológicoy Epidemiológico Coordinador del Registro Central de Cáncer.

12. Programa de Oncología. Ministerio PP Salud. E-mail lgcapote@yahoo.es

13. OPS OMS Cáncer Cervicouterino - Pan American Health Organization

https://www.paho.org/hq/index.php?option cancer 1872\%3Acancer 19 abr. 2018

14. De Sanjosé $S$, Diaz $M$, Castellsagué $X$, Clifford $G$, Bruni L, Muñoz N, Bosch FX. Worldwide prevalence and genotype distribution of cervical human papillomavirus DNA in women with normal cytology: a meta-analysis. Lancet Infect Dis. 2007; 7(7):453-9. Review. PubMed PMID: 17597569.

15. Malca $M$, López $A$, Álvarez $M$, Santos $C$. ¿Preservación de la fertilidad en cáncer de cérvix? Es posible. Rev. Peruana ginecol. obstet. Perú 2013; 59(3): 43-47.

16. Ministerio de Salud del Perú. Análisis de la situación del cáncer en el Perú 2013. Dirección General de Epidemiología. Lima-Perú; 2013.

17. Boletín epidemiológico del Perú - Dirección General de Epidemiología

www.dge.gob.pe/portal/docs/vigilancia/boletines/2 017/21.pdf 27 mayo 2017 - Vigilancia Epidemiológica de cáncer basada en registros hospitalarios.

18. Strander B, Andersson-Ellström A, Milsom I, Sparén $P$. Long term risk of invasive cancer after treatment for cervical intraepithelial neoplasia grade 3: population based cohort study. BMJ. 2007 Nov 24 [Citado 14 de mayo de 2011]; 335(7629): from: http://www.bmj.com/content/335/7629/1077.full

19. Böhmer $G$, van den Brule AJ, Brummer $O$, Meijer $C L$, Petry KU. No confirmed case of human papillomavirus DNA-negative cervical intraepithelial neoplasia grade 3 or invasive primary cancer of the uterine cervix among 511 patients. Am J Obstet 
Gynecol. . 2003 Jul [Citado 26 de febrero de 2009]; 189(1):Disponible en: http://cat.inist.fr/?aModele $=$ afficheN\&cpsidt $=150153$ 67

20. WHO/ICO. Information Centre on HPV and Cervical Cancer (HPV Information Centre). Summary report on HPV and cervical cancer statistics in Cuba; 2007. [citado 4 de junio de 2008]. Disponible en: http://who.int./hpvcentre

21. Dunne EF, Unger ER, Sternberg $M$, et al. Prevalence of HPV infection among females in the United States. JAMA. [Internet]. 2007 [Citado 26 de febrero de 2009]; 297(8): [Aprox. 6p.]. Disponible en: http://jama.ama-assn.org/content/297/8/813.full

22. Hinkula $M$, Pukkala $E$, Kyyronen $P$, Laukkanen $P$, Koskela P, Paavonen J, et al. A population-based study on the risk of cervical cancer and cervical intraepithelial neoplasia among grand multiparous women in Finland. Br J Cancer. 2004 Mar 8 [Citado 23de mayo de 2005]; 90(5): Disponible en:http://www.hu.ufsc.br/projeto_hpv/Apopulation-b asedstudyontheriskofcervicalcancerand.pdf

23. Berlin Grace VM. HPV type 18 is more oncopotent than HPV 16 in uterine cervical carcinogenesis although HPV16 is the prevalent type in Chennai, India. Indian Journal of Cancer. 2009 July_September [Citado 26 de octubre de 2009]; 46 (3): Disponible: http://www.indianjcancer.com/article.asp?issn=001909X;year $=2009$; volume $=46$; issue $=3$; page $=203$; epage $=207$; aulast $=$ Berlin

24. Kramer A, Schwebke I, Kampf G. How long do nosocomial pathogens persist on inanimate surfaces? A systematic review. BMC Infect Dis. [Internet]. 2006 Aug 16 [Citado 26 de febrero de 2009]; 6. Disponible en: http://www.biomedcentral.com/1471-2334/6/130

25. Centers for Disease Control and Prevention. Vaccines and Preventable Diseases: HPV vaccine questions andanswers. Disponible en: http://www.cdc.gov/vaccines/vpd-vac/hpv/vac-faqs.h tm [citado en enero de 2007]

26. Chin Hong PV. Cutting Human Papillomavirus infection in men. J Infect Dis. [Internet]. 2008 [Citado 20 de agosto de 2011]; 197(6): Disponible en: http://jid.oxfordjournals.org/content/197/6/781.short

27. Stewart J 3rd, Bevans-Wilkins K, Ye C, Kurtycz DF. Clear-cell endocervical adenocarcinoma in a 19-year-old woman. Diagn Cytopatho]. 2006 Dec [Citado 23 de mayo de 2009]. Disponible en: http://www.ncbi.nlm.nih.gov/pubmed/17183758

28. Safeian M, Kiddugavu M, Gravitt PE, Gange SJ, Ssekasanvu J, Murokora D, et al. Prevalence and risk factors for carcinogenic human papillomavirus infectios in rural Rakai, Uganda. Sexually Transmitted Infections. 2008 [Citado 23 de mayo de 2009]; 4(2). Disponible en: http://sti.bmj.com/content/early/2008/04/02/sti.2007. 027318.short

29. Appleby P, Beral V, Berrington de González A, Colin D, Franceschi S, Goodhill A, et al. Cervical cancer and hormonal contraceptives: collaborative reanalysis of individual data for 16,573 women with cervical cancer and 35,509 women without cervical cancer from 24 epidemiological studies. Lancet. $2007 \mathrm{Nov}$ 10 [Citado 17 de agosto de 2009]; 370(9599). Disponible http://www.ncbi.nlm.nih.gov/pubmed/17993361

30. Serraino D, Dal Maso L, La Vecchia C, Franceschi S. Invasive cervical cancer as an AIDS-defining illness in Europe. AIDS. 2002 Mar 29 [Citado 23 de mayo de 2009]; 16(5). Disponible en: http://www.ncbi.nlm.nih.gov/pubmed/11964535.

31. Collins S, Rollason TP, Young LS, Woodman CBJ. Cigarette smoking is an independent risk factor for cervical intraepithelial neoplasia in young women: a longitudinal study. Eur J cancer. 2010 Jan [Citado 26 de marzo de 2010]; 46 (2). Disponible en: http://www.ncbi.nlm.nih.gov/pmc/articles/PMC2808 403.

32. Tratamiento del cáncer de cuello uterino avanzado y cuidados paliativos para las pacientes Adaptado de: Wright TC y Schiffman M. Adding a Test for Human Papillomavirus DNA to Cervical-Cancer Screening . The New England Journal of Medicine. 2003;348:489-490.

33. Sanabria Negrín JG. Virus del Papiloma Humano. Revisión Bibliográfica. Revista de Ciencias Médicas de Pinar del Río]. 2009 [Citado 26 de marzo de 2010]; 13(4): Disponible en:

http://scielo.sld.cu/scielo.php?script=sci_arttext\&pi $\mathrm{d}=$ S1561-31942009000400019\&lng=en

34. Cárdenas R, Pérez $D$, Cruz RJ, Torres, Pérez JA. Caracterización de mujeres de Las Tunas con lesiones cérvico uterinas. Revista Electrónica Dr. Zoilo E. Marinello Vidaurreta. Cuba 2017; 41

35. Tartabull G, Scull C, Duarte A, López D, Sosa D. Correlación cito-histológica de las lesiones intraepiteliales del cérvix. Revista Médica Ciego de Ávila; Cuba 2013; 19(1): 14-22

36. Kaferle JE, Malouin JM. Evaluation and Management of the AGUS Papanicolaou Smear. Am Fam Physician. 2001 [Citado 23 de mayo de 2009]; 63(11). Disponible en: http://www.aafp.org/afp/20010601/2239.html

37. Kjaer S, Høgdall E, Frederiksen $K$, Munk C, van den Brule A, Svare E, et al. The absolute risk of cervical abnormalities in high-risk human papillomavirus-positive, cytologically normal women over a 10-year period. Cáncer Res. 2006 Nov 1 [Citado 30 de marzo de 2008]; 66(21. Disponible en:http://cancerres.aacrjournals.org/content/66/21/ 10630.abstract

38. Hoffman BL, Schorge JO, Schaffer JI, Halvorson LM, Bradshaw KD, Cunningham G. Williams Ginecología. 2da Edición. México: Editorial McGraw Hill; 2014.

39. IARC. Atlas de Citología; 2009.

40. CDC. Cervical Cancer Screening]. USA: Centers for Disease Control and Prevention; 2011. [Actualizado el 29 Marzo de 2011; Citado 15 de mayo de 2011]. 
Disponible en:

http://www.cdc.gov/cancer/cervical/basic_info/screen ing.htm

41. Dudding N, Renshaw AA, Ellis K. Rapid pre-screening is more sensitive in liquid-based cytology than in conventional smears. Acta Cytologica. [Internet]. 2011 [Citado 15 de mayo de 2011]; 55(1): Disponible en: http://content.karger.com/produktedb/produkte.asp? doi $=320906$

42. Sasieni P, Castanon A, Cuzick J. Effectiveness of cervical screening with age: population based case-control study of prospectively recorded data. BMJ. 2009 [Citado 24 de Julio de 2010]; 339: Disponible en:

http://www.bmj.com/content/339/bmj.b2968.full

43. Cuba, Ministerio de Salud Pública. Programa de Detección oportuna del Cáncer Cervicouterino; 1968

44. ACOG Committee on Gynecological Practice. ACOG committee opinion No. 431: routine pelvic examination and cervical cytology screening. Obstet Gynecol. 2009 May [Citado 15 de mayo de 2011]; 113(5): Disponible en:

http://www.ncbi.nlm.nih.gov/pubmed/19384150

45. GUÍA DE PRÁCTICA CLÍNICA PARA LA PREVENCIÓN Y MANEJO DEL CÁNCER DE CUELLO UTERINO (RESOLUCIÓN MINISTERIAL N 1013-2016/MINSA) Página Web: http://www.minsa.gob.pe el 29 de diciembre del 2016.

46. Gök M, Rozendaal L, Berkhof J, Visser O, Meijer CJLM, van Kemenade FJ. Cytology history preceding cervical cancer diagnosis: a regional analysis of 286 cases. Brit J Cancer. [Internet]. 2011 [Citado 15 de mayo de 2011]; Disponible en:

http://www.nature.com/bjc/journal/v104/n4/full/6606 067a.html

47. Ferris DG, Litaker M. Prediction of cervical histologic results using an abbreviated Reid Colposcopic Index during ALTS. Am J Obstet Gynecol. 2006 [Citado 17 de ago de 2009]; 194(3)]. Disponible en: http://www.ncbi.nlm.nih.gov/pubmed/16522401.

48. Ferris DG, Litaker M. Prediction of cervical histologic results using an abbreviated Reid Colposcopic Index during ALTS. Am J Obstet Gynecol. 2006 [Citado 17 de agost de 2009]; 194(3). Disponible en: http://www.ncbi.nlm.nih.gov/pubmed/16522401

49. Gaffikin L, McGrath JA, Arbyn M, Blumenthal PD. Visual inspection with acetic acid as a cervical cancer test: accuracy validated using latent class analysis. BMC Med Res Methodol 2007 [Citado 17 de ago de 2009]; 7]. Disponible en:

http://www.ncbi.nlm.nih.gov/pubmed/17663796.

50. IARC. Screening Group. Multimedia. Presentations. 2005 June. International AGency for Research on Cancer. CD-ROM. Disponible en: http://screening.iarc.fr.

51. Cordero J, Maestri I, Gil R. Métodos actuales de diagnóstico del cáncer de cuello uterino. Revista de Ciencias Médicas. Cuba 2015; 21(1): 130-140

52. IARC. WHO histological classification of tumours of the uterine cervix. [CD ROM]. 2007 47. Sarduy Nápoles MR. Neoplasia Intraepitelial Cervical. Preámbulo del cáncer cérvicouterino. Rev Cubana Obstet Ginecol. 2008 Ago [citado 2009 Jun 04]; 34(2). Disponible en:

http://scielo.sld.cu/scielo.php?script=sci_arttext\&pi $d=$ S0138-600X2008000200004\&lng=es

53. Martin-Hirsch PL, Paraskevaidis $E$, Kitchener $H$. Surgery for cervical intraepithelial neoplasia. Cochrane Database Syst Rev 2000 ;( 2):CD001318.

54. Sarduy Nápoles MR. Neoplasia Intraepitelial Cervical. Preámbulo del cáncer cérvicouterino. Rev Cubana Obstet Ginecol. 2008 Ago [citado 2009 Jun 04]; 34(2). Disponible en: http://scielo.sld.cu/scielo.php?script=sci_arttext\&pi $d=S 0138-600 X 2008000200004 \&$ Ing =es.

55. Wright JD, Davila RM, Pinto KR, Merritt DF, Gibb RK, Rader JS, et al. Cervical dysplasia in adolescents. Obstet Gynecol. [Internet]. 2005 Jul [Citado 17 de ago de 2009]; 106(1): Disponible en: http://www.ncbi.nlm.nih.gov/pubmed/15994625.

56. Lu CH, Liu FS, Kuo CJ, Chang CC, Ho ES. Prediction of persistence or recurrence after conization for cervical intraepithelial neoplasia III. Obstet Gynecol. 2006 Apr [Citado 17 de ago de 2009]; 107(4). Disponible en: http://www.ncbi.nlm.nih.gov/pubmed/16582119.

57. Cai B, Ronnett BM, Stoler M, Ferenczy A, Kurman RJ, Sadow $D$, et al. Longitudinal evaluation of interobserver and intraobserver agreement of cervical intraepithelial neoplasia diagnosis among an experienced panel of gynecologic pathologists. Am J surg Pathol. 2007 Dec [Citado 17 de ago de 2009]; 31 (12). Disponible en: http://preview.ncbi.nlm.nih.gov/pubmed/18043039.

58. Sironi S, Buda A, Picchio M, Perego P, Moreni $R$, Pellegrino $A$, et al. Lymph node metastasis in patients with clinical early-stage cervical cancer: detection with integrated FDG PET/CT. Radiology. 2006 Jan [Citado 04 de ago de 2009]; 238(1). Disponible en: http://www.ncbi.nlm.nih.gov/pubmed/16304090/.

59. Cortés Bordoy J, García de Paredes M, Muñoz Zato E, Martinón Torres F, Torné Blade A, García Rojas A, et al. Vacunas profilácticas frente al virus del papiloma humano: Documento de consenso 2008. SEMERGEN. 2009 [Citado 17 de febrero de 2009]; 35(1). Disponible en: http://www.elsevier.es/en/node/2070893.

60. Wensveen CW, Kagie MJ, Veldhuizen RW, Trimbos $\mathrm{JB}$, Boon ME. Combining HPV and MIB-1 tests reduces the number of colposcopies in women with equivocal cytology. Acta Obstet Gynecol Scand. 2006 [Citado el 20 de julio de 2009]. Disponible . http://www.ncbi.nlm.nih.gov/entrez/query.fcgi?db= pubmed\&cmd =Retrieve\&dopt=AbstractPlus\&list_u ids $=17260227 \&$

61. Shastri SS, Dinshaw K, Amin G, Goswami S, Patil S, Chinoy $R$, et al. Concurrent evaluation of visual, 
cytological and HPV testing as screening methods for the early detection of cervical neoplasia in Mumbai, India. Bull World Health Organ. 2005 Mar [Citado el 20 de marzo de 2008]; 83(3). Disponible:http://www.ncbi.nlm.nih.gov/entrez/query. fcgi? itool=abstractplus $\& \mathrm{db}=$ pubmed $\& \mathrm{cmd}=$ Retrieve \&dopt=abstractplus\&list_uids $=15798842$.

62. Sankaranarayanan R, Esmy PO, Rajkumar R, Muwonge R, Swaminathan R, Shanthakumari S, et al. Effect of visual screening on cervical cancer incidence and mortality in Tamil Nadu, India: a cluster-randomised trial. Lancet. [Internet]. 2007 Aug 4 [Citado el 17 de ago de 2009]; 370(9585): Disponible en:

http://www.ncbi.nlm.nih.gov/pubmed/17679017?

63. Hellsten C, Lindqvist PG, Sjöström K. A longitudinal study of sexual functioning in women referred for colposcopy: a 2-year follow up. BJOG. 2008 [Citado 31 de diciembre de 2009]; 115(2): Disponible en: http://www.ncbi.nlm.nih.gov/pubmed/17903228

\section{PANACEA

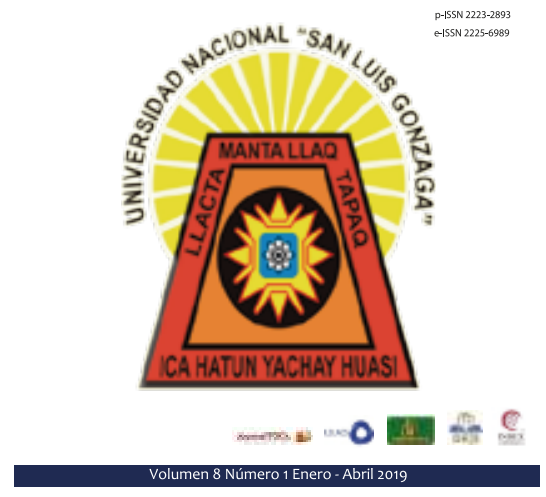

